Cahiers d'études africaines

\title{
Goirand, Camille (dir.). - Lusotopie 2003. Violence et contrôle de la violence au Brésil, en Afrique et à Goa
}

Paris, Karthala, 2004, 562 p.

Elisabetta Maino

\section{OpenEdition}

\section{Journals}

Édition électronique

URL : http://journals.openedition.org/etudesafricaines/6270

DOI : 10.4000 /etudesafricaines.6270

ISSN : $1777-5353$

\section{Éditeur}

Éditions de l'EHESS

Édition imprimée

Date de publication : 1 décembre 2006

ISBN : 978-2-7132-2129-3

ISSN : 0008-0055

\section{Référence électronique}

Elisabetta Maino, "Goirand, Camille (dir.). - Lusotopie 2003. Violence et contrôle de la violence au Brésil, en Afrique et à Goa », Cahiers d'études africaines [En ligne], 184 | 2006, mis en ligne le 08 décembre 2006, consulté le 24 septembre 2020. URL : http://journals.openedition.org/etudesafricaines/6270 ; DOI : https://doi.org/10.4000/etudesafricaines.6270

Ce document a été généré automatiquement le 24 septembre 2020.

(c) Cahiers d'Études africaines 


\title{
Goirand, Camille (dir.). - Lusotopie 2003. Violence et contrôle de la violence au Brésil, en Afrique et à Goa
}

Paris, Karthala, 2004, 562 p.

\author{
Elisabetta Maino
}

1 On ne peut que se réjouir de cette initiative éditoriale qui, depuis désormais une décennie, consacre une revue pluridisciplinaire aux sociétés d'influence historique lusitaine. Si le critère de découpage peut paraître peu novateur, il convient de souligner que Lusotopie a le mérite de réunir et faire circuler des travaux sur des pays plutôt négligés, hormis le Brésil, par les sciences sociales francophones. L'acceptation de textes en français, portugais, anglais et même espagnol, facilite la diversification des auteurs et élargit le potentiel de lecteurs. De plus, les articles sont disponibles en ligne dès la sortie du numéro suivant.

2 Ce volume, comme les autres, est dédié à une thématique fédératrice dans un propos comparatiste spécifique à l'aire dite lusophone qui se prête, évidemment, aux comparaisons avec les recherches menées ailleurs. Coordonné par Camille Goirand, le dossier de 2003 examine les caractéristiques des pratiques sociales violentes, s'interroge sur leurs causes historiques ainsi que sur les changements des normes sociales provoqués par la dissémination de la violence et, enfin, questionne l'efficacité des politiques de sécurité publique.

3 Pour ce qui est des anciennes colonies portugaises d'Afrique, João Paulo Borges Coelho (« Da violência colonial ordenada à ordem pós-colonial violenta »: 175-193) défend la thèse selon laquelle la mise en ordre violente d'une société tient à son degré de militarisation. Ainsi, le «potentiel de violence » cumulé pendant les guerres coloniales a trouvé un terrain favorable dans "l'africanisation" des conflits avant même les indépendances, c'est-à-dire dans les luttes intestines au sein des mouvements anticolonialistes. Deux autres facteurs liés au premier ont contribué à la transformation des guerres de libération en guerres civiles: d'une part, l'implication des pays limitrophes dans les conflits armés dans le cadre de la guerre froide et, d'autre 
part, l'autoritarisme du parti unique pour imposer son propre modèle d'État postcolonial aux opposants nationaux. C'est pourquoi l'argument usuel des tensions sociales suscitées par la réinsertion des Africains ayant combattu dans les rangs de l'armée coloniale ne saurait expliquer la continuité du dispositif de militarisation de la société post-indépendance.

Inge Brinkman («War and Identity in Angola »: 195-221) analyse les transformations des catégories identitaires dans un contexte de guerre civile à partir des populations déplacées du nord et du sud-est de l'Angola. Elle montre comment, en deçà de l'hétérogénéité des trajectoires individuelles, dans le premier cas les assignations identitaires s'agencent autour des dichotomies Luandais = Angola versus Bakongo = Zaïre superposant ainsi local et national. Dans l'autre cas, les identités s'organisent en opposant ville et brousse, chaque terme étant respectivement associé au MPLA, le partiÉtat, et à l'UNITA, son adversaire armé, et cela en dépit des appartenances politiques réelles.

5 Gerhard Seibert ("The Bloodless Coup of July 16 in São Tomé e Príncipe » : 245-260) décrit le déroulement d'une tentative de coup d'État menée en 2003 dans l'archipel par des militaires aidés par des civils appartenant à un minuscule parti. Leur objectif était de dénoncer les conditions de vie misérables de la population face à l'insouciance des gouvernants corrompus, et de réclamer plus de transparence et une répartition plus juste de la rente. Si, à l'instar du soulèvement militaire de 1995, le but n'était pas la prise de pouvoir, il aurait été profitable de discuter la pertinence de la qualification " coup d'État » donnée à ces événements et ainsi saisir le rôle des rapports de force dans la vie politique insulaire. Mais, selon Seibert, les véritables instigateurs sont les civils qui, déjà impliqués dans la tentative du coup d'État de 1988 et ex-mercenaires sur le continent africain, étaient mus par des revendications « corporatistes » à l'instar de celles des militaires de 1995. Cette lecture, d'une part confond motivations initiales et avantages promis lors des accords, et d'autre part, minimise l'accentuation des crises politiques et des tensions sociales à l'aune des transformations en cours.

6 L'article hors dossier "Business and Politics in São Tomé e Príncipe : From Cocoa Monoculture to Petro-State " (Frynas, Wood \& Soares de Oliveira: 33-58) expose, de façon complémentaire, les tortueux chemins empruntés par l'élite politique santoméenne dans la négociation des droits d'exploitation pétrolière, dont une bonne partie des bénéfices profiteront à une obscure compagnie (enregistrée aux États-Unis) désormais dirigée par un homme d'affaires nigérien proche du président Obasanjo. L'existence d'une aire d'exploitation commune aux deux pays explique donc l'empressement de ce dernier pour restaurer le statu quo à São Tomé e Príncipe lors de la crise de juillet 2003.

7 Dans " "The traditional lion is dead": The Ambivalent Presence of Tradition and the Relation Between Politics and Violence in Mozambique»(263-281), Bjorn Enge Bertelsen s'intéresse à la construction discursive par les deux principaux partis mozambicains, Frelimo et Renamo, d'une continuité symbolique avec le pouvoir «traditionnel », et montre comment, de façon ambiguë, les pratiques violentes du passé participent de leur légitimation actuelle, intégrant par là les niveaux local, régional et national.

8 Enfin, Jordane Bertrand, à travers « Le cas Cardoso au Mozambique. La violence et la corruption en procès" (453-463) illustre comment le procès aux assassins d'un journaliste qui menait une enquête sur les tramages d'un énorme détournement de 
fonds lors de la privatisation de la principale banque du pays, a incarné les aspirations démocratiques de la société civile. Si la seule lourde condamnation des sicaires ne résout pas les questions d'impunité des réseaux mafieux qui opèrent en connivence avec des autorités politiques complaisantes, ce procès a au moins été l'occasion pour les moyens de communication de revendiquer une réelle liberté d'information et, pour une partie de la magistrature, d'afficher son autonomie vis-à-vis du pouvoir politique. no mato. Imagens sobre os portugueses em discursos rurais moçambicanos »: 91-112) sur les représentations véhiculées par le terme Ma-Tuga, appellation autrefois réservée aux colons portugais qui, en milieu rural, désigne également les membres de l'élite politique et économique d'origine urbaine, c'est-à-dire ceux qui occupent les positions des Blancs. La mémoire de la domination coloniale acquiert ainsi une portée critique des structures d'encadrement étatique de la société actuelle.

L'article de Juliana Santil « Hôtel XXI » (153-162) traite de l'absence de rencontre entre les Brésiliens et les petits commerçants africains lusophones, surtout angolais et capverdiens, qui vont s'approvisionner à São Paulo. Les représentations réciproques sont biaisées par des "interférences coloniales", véritable legs d'un discours lusotropicaliste construit davantage sur les sentiments de supériorité/infériorité que sur une supposée affinité culturelle. Ainsi, les clichés sur le «Brésil-violence» des Africains, auxquels les Brésiliens opposent ceux sur l'Afrique des guerres ethniques et de la pauvreté, coexistent avec l'image du «Brésil-puissance » qui remplace la colonialité portugaise.

11 Dans un registre plus historique, Liazzat J. K. Bonate («The Ascendance of Angoche: The Politics of Kinship and Territory in Nineteenth Century Northern Mozambique »: 155-142) affirme que l'expansion d'une puissance régionale formée par l'archipel d'Angoche et l'actuelle province de Nampula reposait moins sur sa situation géographique et son implication dans le trafic négrier que sur la capacité des respectives élites à tisser un réseau d'allégeances sur la double logique de la proximité territoriale et de la parenté. La politique portugaise d'occupation effective n'ayant pas été homogène, les rapports d'Angoche avec les anciens commerçants portugais n'étaient pas organisés par le simple principe de résistance à la conquête, mais par une multiplicité d'interactions et de médiations entre les divers acteurs. Ce n'est qu'en 1910 que la région fut militairement soumise à la mise en ordre coloniale avec l'appui des petits chefs locaux, tandis que les dirigeants principaux furent tués ou déportés.

12 Pour sa part, Mia Couto ( $\mathrm{A}$ economia e a fronteira da cultura » :143-151) incite les Mozambicains à décoloniser leur pensée, à abandonner les postures de victimisation et les registres d'analyse du catéchisme économiciste des bailleurs internationaux pour assumer pleinement la responsabilité historique de construire une alternative singulière, adaptée à la réalité du pays, sans pour autant tomber dans les travers du relativisme culturel. Invitation à être soi-même, que l'on peut étendre aux autres pays africains. 